\title{
Survival of primary, but not of cancer cells after combined PIk1- HDAC inhibition
}

\author{
Lisa Lange ${ }^{1}$, Peter Hemmerich ${ }^{2}$, Birgit Spänkuch ${ }^{1}$ \\ ${ }^{1}$ Friedrich-Schiller-University, CMB, Institute for Biochemistry and Biophysics, 07745 Jena, Germany \\ ${ }^{2}$ Leibniz-Institute for Age Research-Fritz Lipmann Institute, JenAge (Jena Centre for Systems Biology of Aging), 07745 Jena, \\ Germany
}

Correspondence to:

Birgit Spänkuch, e-mail: birgit.spaenkuch@uni-jena.de

Keywords: polo-like kinase 1, HDAC, p21, cell cycle, cancer

Abbreviations: PIk1 - polo-like kinase 1; HDAC - histone deacetylase; HDACi - histone deacetylase inhibitor; SAHA - suberoylanilide hydroxamic acid; pRb - phospho-Rb

Received: February 24, $2015 \quad$ Accepted: June 16, 2015

Published: June 26, 2015

\section{ABSTRACT}

In the current study we examined the combination of SAHA and SBE13 in cancer and non-cancer cells. HeLa cells displayed a synergistically reduced cell proliferation, which was much weaker in hTERT-RPE1 or NIH-3T3 cells. Cell cycle distribution differed in HeLa, hTERT-RPE1 and NIH-3T3 cells. SAHA-treated HeLa cells showed slightly increasing cell numbers in G2/M phase, but after combination with SBE13 strongly elevated cell numbers in G2/M and S phase, accompanied by decreasing $\mathbf{~ O 0}$ / G1 percentages. hTERT-RPE1 and NIH-3T3 cells showed strongly enriched cell numbers in G0/G1 phase. Western blot and quantitative real time analyses revealed reduced PIk1 mRNA and protein in all cells. p21 protein was strongly induced in cancer, but not in non-cancer cells, corresponding to a different localization in immunofluorescence studies. Additionally, these revealed an abundantly present pRb protein in HeLa cells after any treatment but almost completely vanished pRb staining in treated hTERT-RPE1 cells. These differences could be approved in Western blots against Parp and Caspase 3, which were activated in HeLa, but not in hTERT-RPE1 cells. Thus, we observed for the first time a differential effect of cancer versus non-cancer cells after treatment with SAHA and SBE13, which might be due to the dual role of p21.

\section{INTRODUCTION}

The search for new therapeutic strategies is an important research field in translational cancer research. Many strategies inhibit one or more cancer-relevant genes with the aim to inhibit cancer cell proliferation by inhibiting the expression or activity of the targeted genes. One promising strategy to improve therapy is the use of small molecule kinase inhibitors, which represent essential tools in basic and translational research.

One attractive target gene in the fields of signaling research and cancer therapy is the serine/threonine kinase Plk1 (polo-like kinase 1) [1], which shows elevated activity in all human tumors [2-4]. Plk1 plays a pivotal role for mitosis and as a measure for the aggressiveness of a tumor due to its important role for the mitotic checkpoints of cancer cells [5-10]. Plk1 has predictive and prognostic value for cancer patients $[10,11]$. Interfering with Plk1 activity and/or expression using dominant-negative mutants, antibody microinjection, antisense oligonucleotides, small interfering RNAs or kinase inhibitors leads to different mistakes in centrosomal maturation, mitotic catastrophe and increased apoptosis in cancer cells [8,11-21]. In addition to its role during mitosis, Plk1 has multiple functions outside of mitosis, for example for checkpoint recovery after DNA damage [11, 22] and for G1/S phase [23].

SBE13, a selective type II Plk1 inhibitor, is able to induce a delay in cell cycle progression, to reduce cell proliferation and to induce apoptosis in a broad range of human cancer cell lines $[16,17]$. SBE13 displayed 1,000-fold selectivity towards Plk family members and did not influence Aurora A activity. SBE13 displayed a differential effect between cancer and primary cells [24] with especially $\mathrm{G} 2 / \mathrm{M}$ arrest in cancer cells and transient G0/G1 arrest in primary cells without any signs of cell death, confirming earlier studies $[18,21]$. 
Histone deacetylases (HDAC) suppress transcription of their specific target genes and are correlated to cancer pathogenesis. They counteract the activity of histone acetyl transferases, which acetylate for example histones to make them accessible for transcription factors. These acetylations are removed by HDACs afterwards. Additionally, it has been described that HDAC inhibitors (HDACi) reduce Plk1 protein, suggesting the combination of Plk1 and HDAC inhibitors to combat cancer [25, 26].

Most of the analyzed tumor cells respond to an inhibition of HDAC with signs of apoptosis, growth/ proliferation arrest, differentiation and altered gene expression. However, in many cases it is unclear whether these effects resulted from an altered gene-expression profile or were caused by toxic effects inherent to the substances employed [27]. Some of them are already tested in clinical studies [28]. Various studies describe an induction of apoptosis by HDACi which is a consequence of nonfunctional cell cycle checkpoints [29, 30]. Interestingly, the reduction of the Cdk inhibitor $\mathrm{p} 21^{\mathrm{WAF} / \mathrm{CIP} 1}$, which is responsible for G1 arrest of cells, can induce HDACiinduced cell death [31,32] although p21 is upregulated by HDACi [33].

In this article, we report the combination of SBE13 with the HDACi SAHA (suberanilohydroxamic acid, Vorinostat) in cancer (HeLa cells) and non-cancer cells (NIH-3T3 and hTERT-RPE1 cells). Potential differential effects were elucidated by the analysis of Plk1 mRNA and protein, the induction of apoptosis, the reduction of proliferation, of $\mathrm{pRb}$ and $\mathrm{p} 21$ levels, of protein expression of target proteins, and of the cell cycle distribution.

\section{RESULTS}

\section{Reduced Plk1 mRNA after treatment with SAHA and with SAHA and SBE13 together in HeLa, hTERT-RPE1 and NIH-3T3 cells}

First, we determined the levels of Plk1 mRNA after treatment with SAHA alone and in combination with SBE13 in HeLa (cancer cells), hTERT-RPE1 (nontransformed immortalized) and NIH-3T3 cells (mouse fibroblasts) (Figure 1). In HeLa cells, we observed statistically significantly reduced mRNA levels after single and combinatorial treatment with 1 to $10 \mu \mathrm{M}$ SAHA $(1 \mu \mathrm{M}: 39 \%, p=0.008,2.5 \mu \mathrm{M}: 18 \%, p=0.0004,5 \mu \mathrm{M}$ : $12 \%, p<0.0001,10 \mu \mathrm{M}: 12 \%, p<0.0001)$ alone and with 1 to $5 \mu \mathrm{M}$ SAHA in combination with $1 \mu \mathrm{M}$ SBE13 $(1 \mu \mathrm{M}$ : $32 \%, p=0.002,2.5 \mu \mathrm{M}: 20 \%, p=0.0007,5 \mu \mathrm{M}: 17 \%$, $p=0.002$ ) (Figure 1A). In hTERT-RPE1 cells effects were comparable with reductions to $46 \%$ with $1 \mu \mathrm{M}$ SAHA $(p=0.0007)$, to $13 \%$ with $2.5 \mu \mathrm{M}$ SAHA $(p<0.0001)$, to $2 \%$ with $5 \mu \mathrm{M}$ SAHA $(p<0.0001)$, and to $2 \%$ with 10 $\mu$ M SAHA $(p<0.0001)$ (Figure 1B). In combination with $10 \mu \mathrm{M}$ SBE13 effects were comparable to SAHA alone showing reductions to $55 \%$ with $1 \mu \mathrm{M}$ SAHA $(p=0.005)$, to $15 \%$ with $2.5 \mu \mathrm{M}$ SAHA ( $p<0.0001$ ), and to $10 \%$ with $5 \mu \mathrm{M}$ SAHA $(p=0.0002)$. In NIH-3T3 cells similar effects could be observed (Figure 1C): reduction to $46 \%$ with $1 \mu \mathrm{M}$ SAHA $(p=0.028)$, to $22 \%$ with $2.5 \mu \mathrm{M}$ SAHA $(p=0.0004)$, to $20 \%$ with $5 \mu \mathrm{M}$ SAHA $(p=0.0003)$, and to $24 \%$ with $10 \mu \mathrm{M}$ SAHA $(p=0.002)$. As in HeLa and in hTERT-RPE1 cells the reduction of Plk1 mRNA was not stronger, but even less pronounced after combinatorial treatment with SBE13 (10 $\mu \mathrm{M}$ SBE13: reduction to $26 \%$ with $2.5 \mu \mathrm{M}$ SAHA $(p=0.0002)$, and to $23 \%$ with $5 \mu \mathrm{M}$ SAHA $(p=0.004)$. These effects suggest an interference of HDAC inhibitors with transcriptional regulation of Plk1 in cancer and in non-cancer cells which is-as expected-not influenced by additional inhibition of Plk1 activity.

\section{Reduced levels of PIk1 protein after treatment with SAHA and with SAHA and SBE13 together in HeLa, hTERT-RPE1 and NIH-3T3 cells}

To analyze whether the reduction of Plk1 mRNA resulted in decreased protein levels we did Western blot analyses targeting Plk1 in HeLa, hTERT-RPE1 and NIH-3T3 cells (Figure 2A, 2C, 2E). In all three cell lines, regardless whether they are cancer cells (HeLa), non-transformed immortalized cells (hTERT-RPE1) or completely normal fibroblasts (NIH-3T3) the Plk1 protein was significantly reduced by SAHA treatment. We observed reductions to levels between 4 and $38 \%$ with 1 to $10 \mu \mathrm{M}$ SAHA alone in HeLa cells, which were less pronounced in combination with $1 \mu \mathrm{M}$ SBE13 (levels of 48-60\%, Figure 2A). In hTERTRPE1 cells Plk1 protein was reduced to levels between 23 and $73 \%$ with $500 \mathrm{nM}-10 \mu \mathrm{M}$ SAHA, and to levels of 16 to $74 \%$ with $10 \mu \mathrm{M}$ SBE13 in combination with 100 nM-5 $\mu$ M SAHA (Figure 2C). Comparable effects could be observed in NIH-3T3 cells, where we detected reductions of Plk1 protein levels to 20 to $51 \%$ with $500 \mathrm{nM}-10 \mu \mathrm{M}$ SAHA alone, and in combination with $10 \mu \mathrm{M}$ SBE13 Plk1 protein levels were reduced to levels of $45-63 \%$ with SAHA concentrations from $100 \mathrm{nM}$ to $5 \mu \mathrm{M}$ (Figure 2E).

\section{Different regulation of $\mathrm{p} 21$ and $\mathrm{pRb}$ after treatment with SAHA and SBE13 in HeLa, hTERT-RPE1 and NIH-3T3 cells}

To further investigate the underlying mechanism we did Western blot analyses in HeLa, hTERT-RPE1 and NIH-3T3 cells targeting p21 (Figure 2B, 2D, 2F). We observed a strong induction of $\mathrm{p} 21$ protein in $\mathrm{HeLa}$ cells after single and combinatorial treatment to levels of nearly $4000 \%$ (Figure 2B), which could not be observed in hTERT-RPE1 cells, which showed p21 levels between 100 and $150 \%$ compared to control cells (Figure 2D). NIH-3T3 cells showed an increase of p21 protein, but this induction was much weaker than in HeLa cells (a maximum induction to approx. 500\% compared to almost $4000 \%$ in HeLa cells, Figure 2F). 
A HeLa SBE13 + SAHA

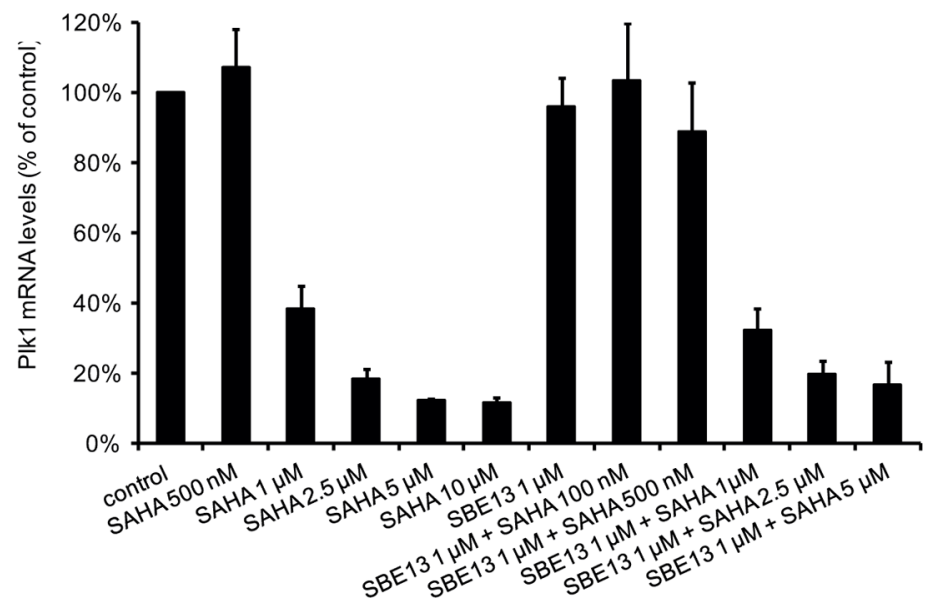

B hTERT-RPE1 SBE13 + SAHA

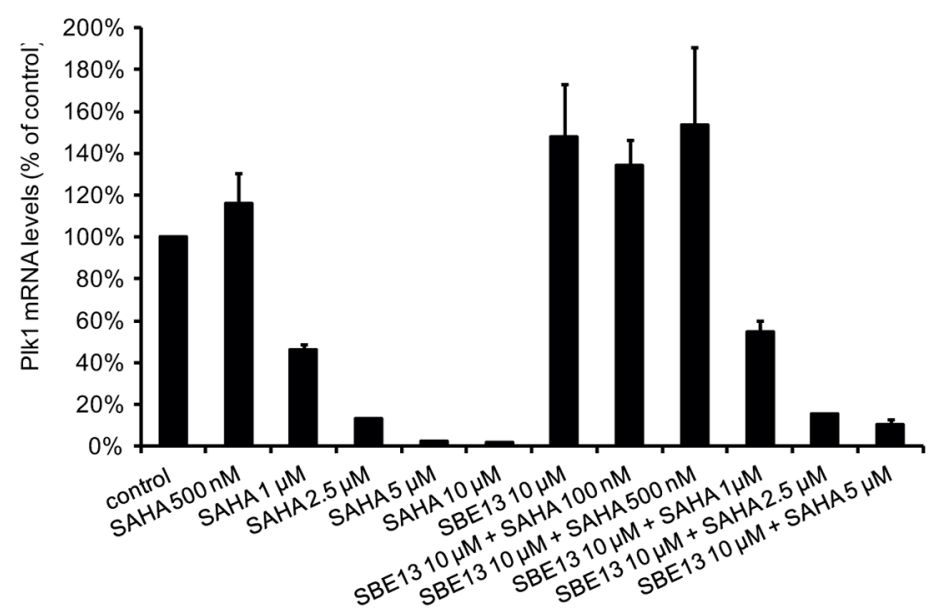

C NIH-3T3 SBE13 + SAHA

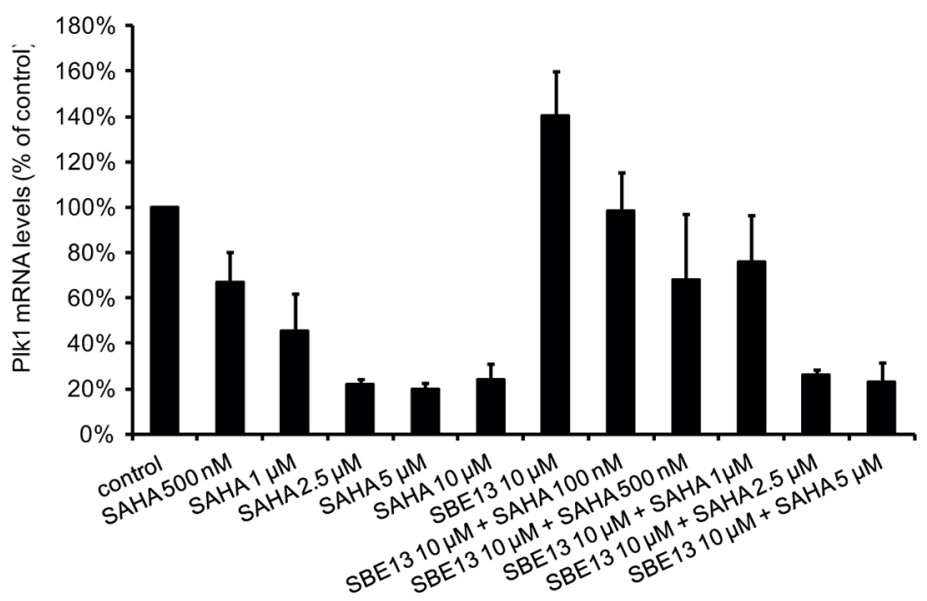

Figure 1: Quantitative real-time analysis of HeLa, hTERT-RPE1 and NIH-3T3 cells after incubation with SAHA and SBE13 using PIk1- and GAPDH-specific primers. Quantitative real-time analysis of Plk1 mRNA levels 24 hrs after treatment with SAHA alone and in combination with SBE13 in HeLa A. hTERT-RPE1 B. and in NIH-3T3 cells C. Graphical summary of gene expression values of treated cells standardized to control cells are shown $(n=3 \times 3$, mean $\pm \mathrm{SD})$. 

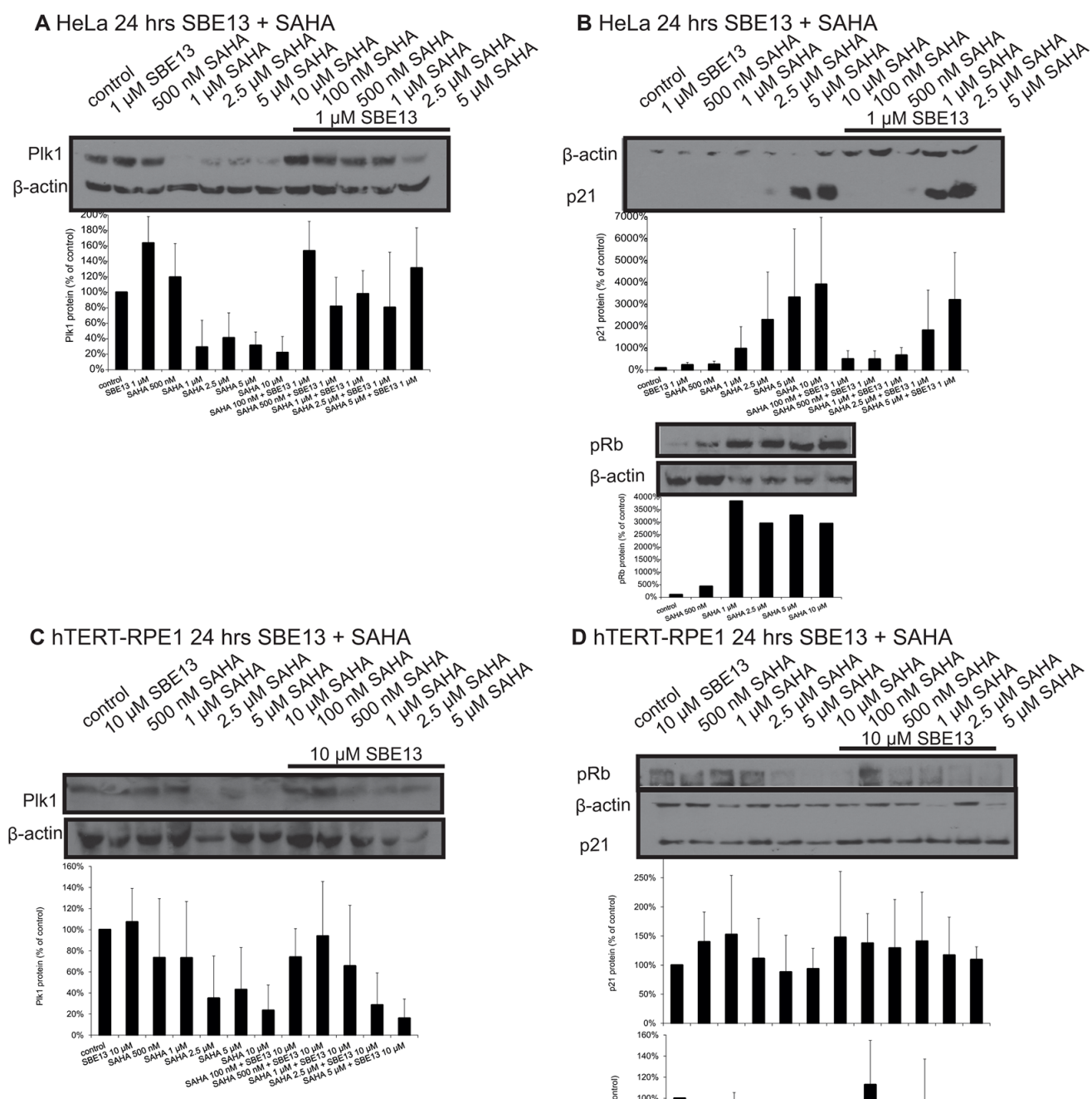

D hTERT-RPE1 24 hrs SBE13 + SAHA

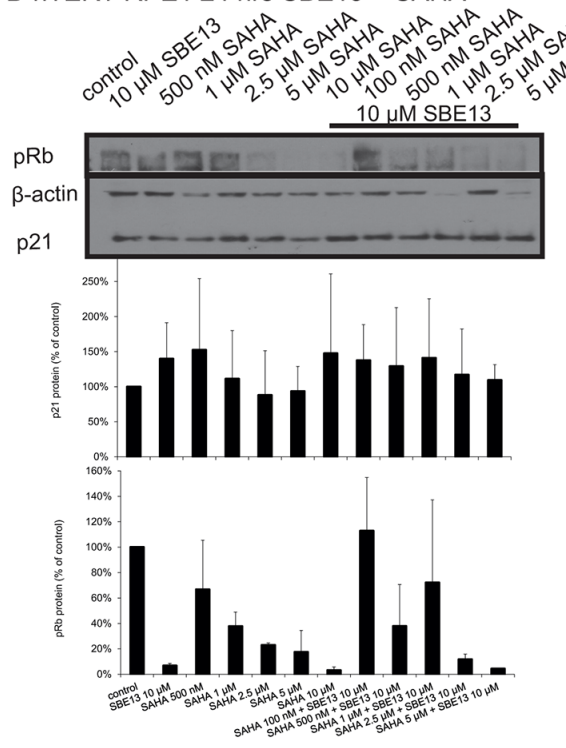

E NIH-3T3 24 hrs SBE13 + SAHA
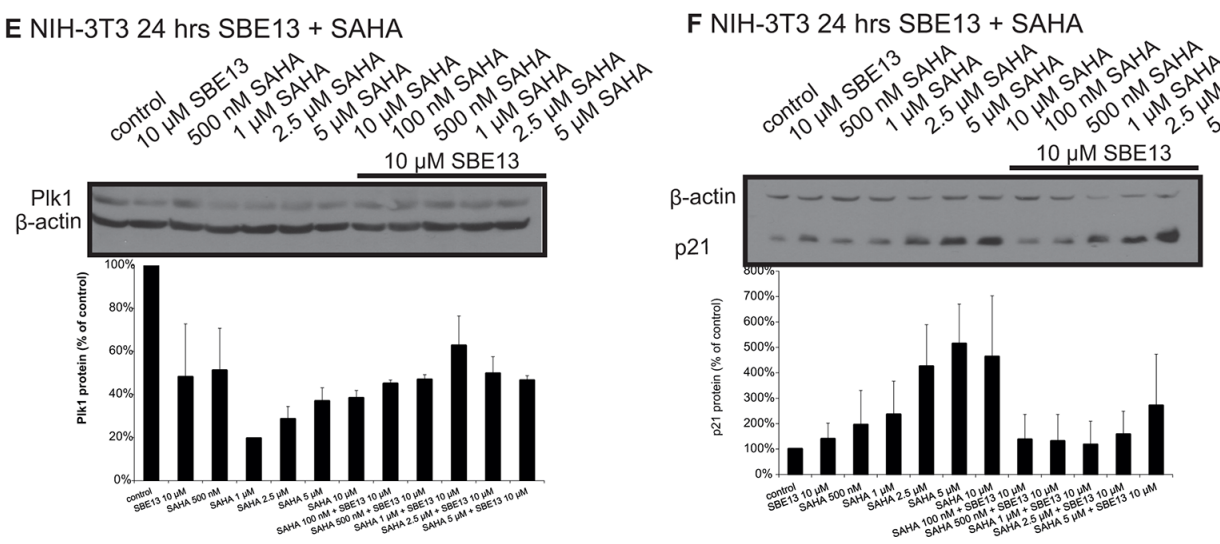

Figure 2: Western Blot analyses of PIk1 and p21 protein expression and of pRb levels in HeLa, hTERT-RPE1 and NIH-3T3 cells after treatment with SAHA and SBE13. Western blot analysis of Plk1 protein expression in HeLa A. hTERT-RPE1 C. and NIH-3T3 cells E. 24 hrs after treatment with SAHA alone and in combination with SBE13 (HeLa cells $1 \mu$ M SBE13, hTERT-RPE1 and $\mathrm{NIH}-3 \mathrm{~T} 3$ cells $10 \mu \mathrm{M}$ ). Western blot analysis of p21 protein expression and pRb levels in HeLa B. hTERT-RPE1 D. and p21 protein expression in NIH-3T3 cells F. 24 hrs after treatment with SAHA alone and in combination with SBE13 (HeLa cells $1 \mu$ M SBE13, hTERTRPE1 and NIH-3T3 cells $10 \mu \mathrm{M}$ ). Figures show representative blots and graphical summary. 
Additionally a cell cycle marker, phosphorylated Rb protein, was analyzed to distinguish between cell cycle arrest types or apoptosis induction in HeLa and hTERTRPE1 cells. hTERT-RPE1 cells showed the expected strong decreased phospho-Rb protein after SBE13 treatment which has been already described [24], but in addition, we could see a strong decrease after SAHA or the combinatorial treatment (Figure 2D, lower panel). In contrast, HeLa cells showed a strong increase of phospho$\mathrm{Rb}$ after SAHA treatment (Figure 2B, lower panel) corresponding to an override of the G1/S checkpoint as observed in earlier studies also for SBE13 [24].

\section{The proteasome inhibitor MG132 does not abrogate the reduction of PIk1 or p21 protein after treatment with SAHA in HeLa cells}

To confirm the real-time PCR data concerning reduced Plk1 mRNA by SAHA treatment and thus to confirm the proposed involvement of transcriptional regulation of Plk1 by HDAC inhibitors, we did Western blot analyses after incubation of HeLa and hTERT-RPE1 cells with SAHA together with the proteasome inhibitor MG132 (Figure 3A, 3B). We observed in both cell types that SAHA reduced Plk1 protein levels very strongly, and that MG132 inhibits the proteasomal degradation of Plk1 demonstrated by strong enrichment after MG132 treatment. But the combination of SAHA with MG132 reduced Plk1 protein compared to MG132 treatment alone, which is a further hint that the reduction of Plk1 protein after SAHA treatment is due to the observed regulation on Plk1 transcription by SAHA and not due to enhanced protein stability.

In addition, we analyzed p21 protein levels after SAHA treatment in combination with MG132 in HeLa cells, and it is obvious that MG132 inhibits the proteasomal degradation of p21, but it is only slightly induced after SAHA treatment with MG132 compared to MG132 alone (Figure 3C).

\section{Cell cycle analysis of HeLa, hTERT-RPE1 and NIH-3T3 cells after treatment with SAHA and SBE13}

We did FACS analyses to determine the cell cycle distribution of HeLa, hTERT-RPE1, and NIH-3T3 cells to examine whether the changes in Plk1 and HDAC activity were associated with an arrest in particular stages of the cell cycle and if these cell cycle arrests are timedependent. In addition, we wanted to figure out whether the absence or presence of a functional G1/S checkpoint influences the cell cycle arrest.

First, we analyzed HeLa cells and observed an increase of cells in $\mathrm{G} 2 / \mathrm{M}$ phase after treatment with SAHA alone and a very prominent increase of cells in $\mathrm{G} 2 / \mathrm{M}$ phase and in $\mathrm{S}$ phase while $\mathrm{G} 0 / \mathrm{G} 1$ phase is strongly reduced after the combination of SAHA with SBE13 (Figure 4A). In hTERT-RPE1 cells, we observed a different cell cycle distribution (Figure 4B): SAHA alone and SAHA together with SBE13 differed only slightly, both inducing a slight increase of cells in G2/M phase and a very strong enrichment of cells in G0/G1 phase. NIH-3T3 cells showed strongly elevated numbers of cells in $\mathrm{G} 0 / \mathrm{G} 1$ phase after single and combinatorial treatment (Figure 4C), which is in concordance with the expectation based on our own studies using SBE13 in primary cells [24].

\section{Immunofluorescence analysis of $\mathrm{pRb}$ and $\mathrm{p} 21$ after treatment with SAHA and SBE13 in HeLa and hTERT-RPE1 cells}

To analyze the differences between HeLa and hTERT-RPE1 cells in more detail we did immunofluorescence analyses in SBE13- and SAHAtreated cancer and non-cancer cells (Figure 4D, 4E). The phospho- $\mathrm{Rb}$ protein is indicative of a functional $\mathrm{G} 1 / \mathrm{S}$ checkpoint, and our own studies using SBE13 revealed an override of G1/S checkpoint in HeLa cells and a G1/S checkpoint arrest in hTERT-RPE1 cells [24]. To analyze whether this difference in $\mathrm{pRb}$ is also the reason for the different response of HeLa and hTERT-RPE1 cells after SBE13 and SAHA treatment we analyzed $\mathrm{pRb}$ protein in both cell types. HeLa cells showed $\mathrm{pRb}$ staining in all control cells with some variation in signal intensity in individual nuclei (Figure 4D, upper panel). After SBE13, SAHA and the combinatorial treatment the $\mathrm{pRb}$ staining pattern stayed essentially the same (Figure 4D, lower three panels). In striking contrast, hTERT-RPE1 control cells displayed many nuclei showing strong staining, and some cells with very low $\mathrm{pRb}$ levels (Figure 4E, upper panel). After treatment with SBE13 or SAHA alone and after the combinatorial treatment $\mathrm{pRb}$ staining was strongly diminished in all nuclei (Figure 4E, lower three panels). These observations suggest a functional p21/pRbmediated G1/S checkpoint in hTERT-RPE1 as a cause for the differences in cell proliferation and apoptosis induction (see below) after the treatments in comparison to HeLa cells.

In addition, we analyzed p21 protein to investigate potential differences in localization or induction/reduction in HeLa and hTERT-RPE1 cells (Figure 4D, 4E). We detected p21 protein in HeLa cells mainly within the nuclei (Figure 4D, upper panel). In contrast, after SBE13 treatment p21 was localized preferentially within the cytoplasm (Figure 4D, second panel). After SAHA treatment, alone or in combination with SBE13, we detected p21 throughout the whole cell without the strong cytoplasmic enrichment as observed for SBE13 alone. hTERT-RPE1 cells did not show this treatment-induced differential p21 (re) localization but was predominantly detectable in the nuclei of these immortalized cells (Figure 4E). 
A HeLa 24 hrs SAHA + MG132

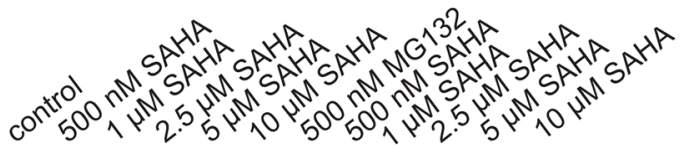

MG132
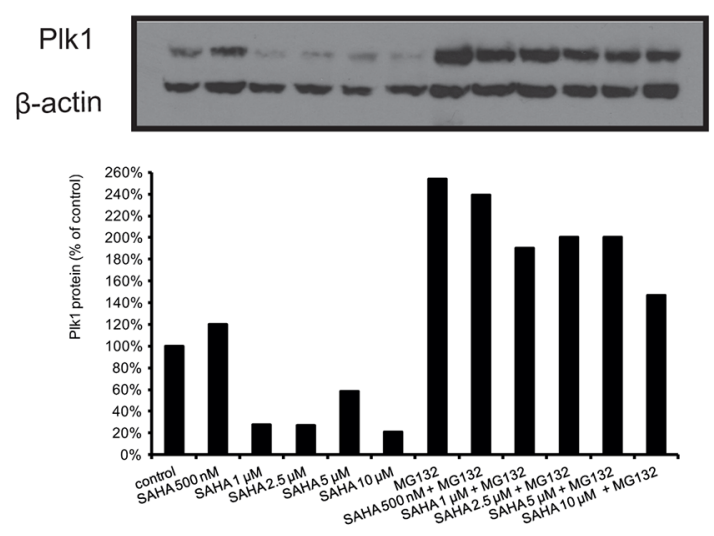

B hTERT-RPE1 24 hrs SAHA + MG132
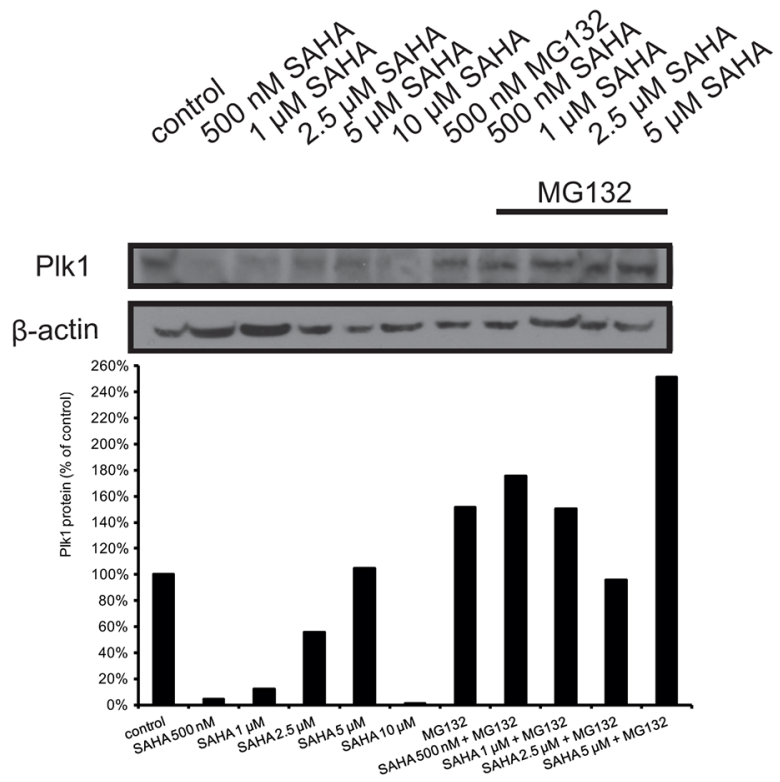

C HeLa 24 hrs SAHA + MG132

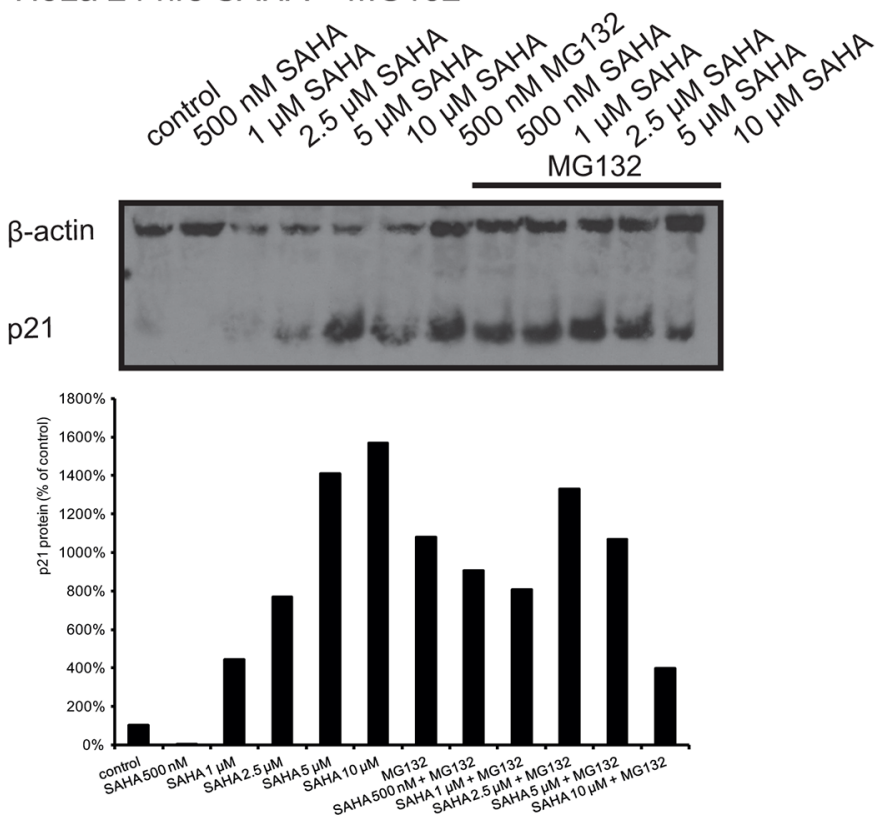

Figure 3: Western Blot analyses of Plk1 protein expression in HeLa and hTERT-RPE1 cells after treatment with SAHA and MG132. Western blot analysis of Plk1 protein expression in HeLa A. and hTERT-RPE1 cells B. 24 hrs after treatment with SAHA and MG132. C. p21 levels in HeLa cells 24 hrs after treatment with SAHA and MG132. Figures show representative blots and graphical summary.

\section{Analysis of apoptosis induction after treatment with SAHA and SBE13 in HeLa and hTERT-RPE1 cells}

We did Western blot analyses targeting Parp and Caspase 3 after SAHA treatment of HeLa and hTERTRPE1 cells to determine potentially different reactions of cancer and non-cancer cells to SAHA treatment. We observed strikingly differing induction of Parp cleavage and Pro-Caspase 3 activation (Figure 5): In HeLa cells an increasing Parp cleavage could already be detected after treatment with $1 \mu \mathrm{M}$ SAHA (Figure 5A), while hTERT-RPE1 cells did not show any Parp cleavage up to $10 \mu \mathrm{M}$ SAHA, but only an increase of the cleavage product after treatment with $25 \mu \mathrm{M}$ SAHA (Figure 5B). The same observation could be made for activation of ProCaspase 3 with almost no induction in hTERT-RPE1 cells, while in HeLa cells Pro-Caspase 3 was already activated 


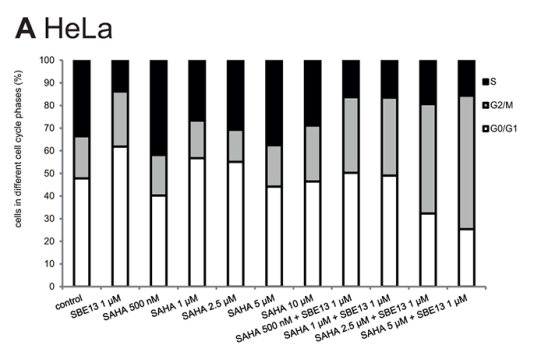

bastumese
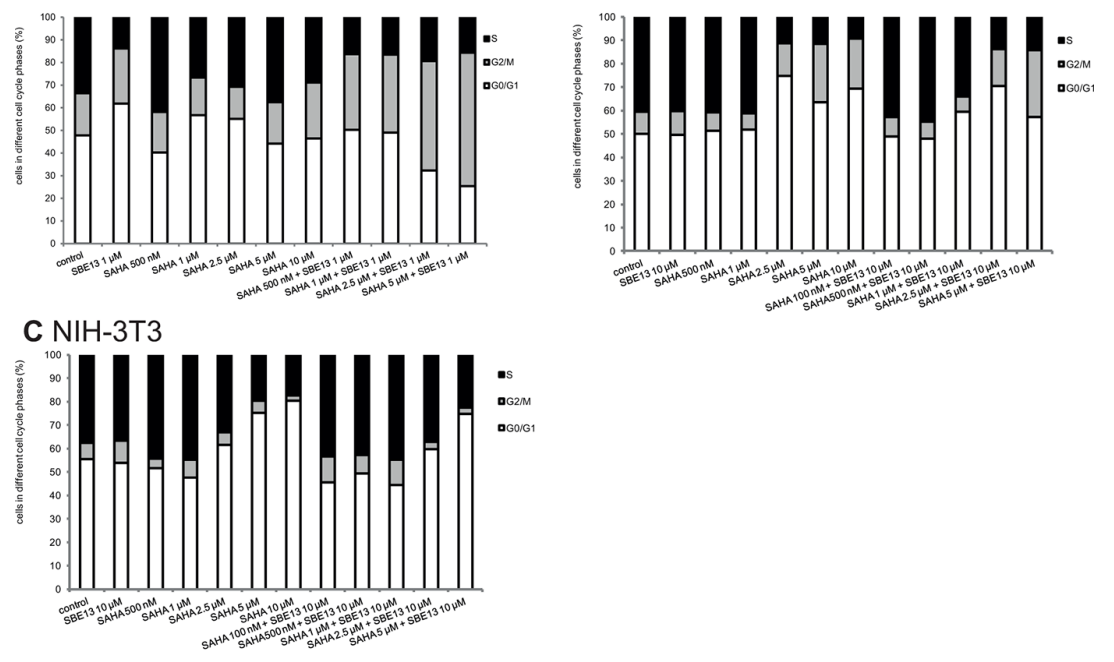

D HeLa

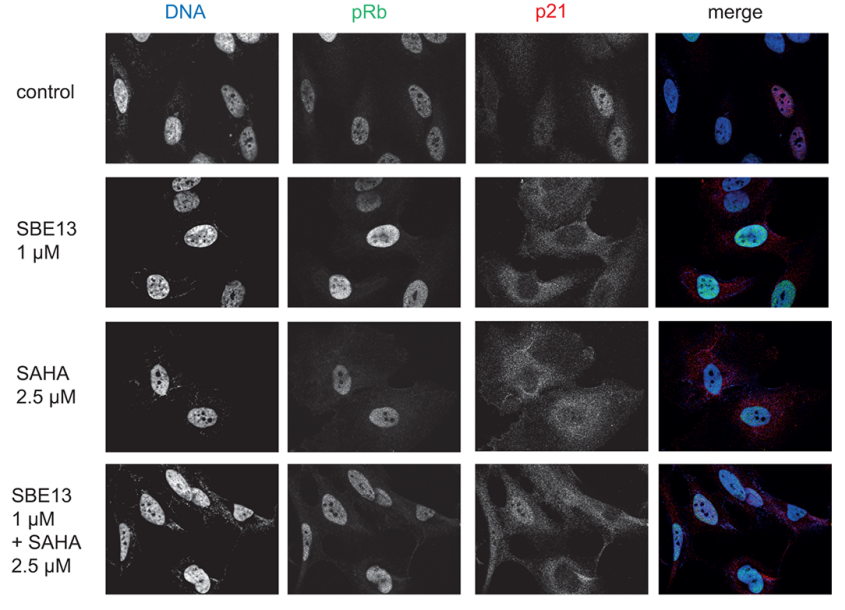

E hTERT-RPE1

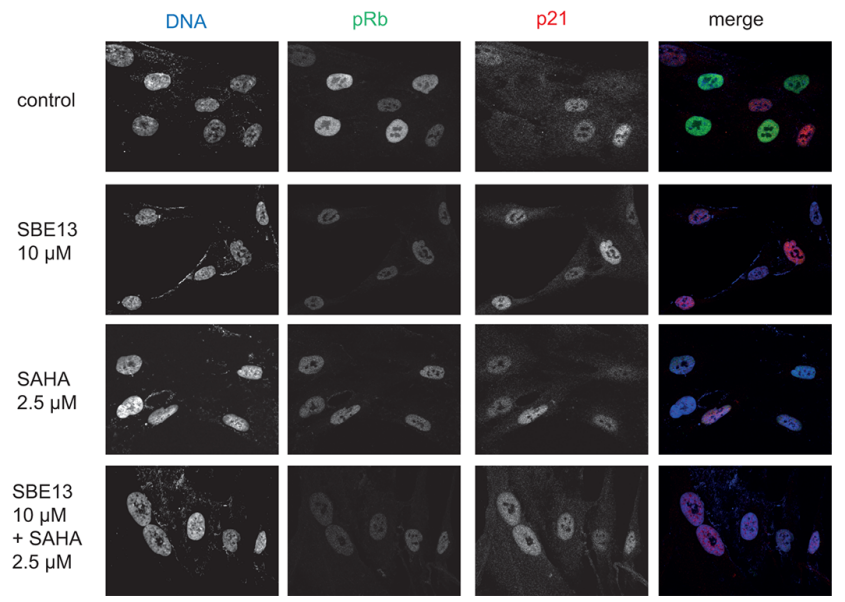

Figure 4: Effect of SAHA and SBE13 on cell cycle distribution of HeLa A. hTERT-RPE1 B. and NIH-3T3 cells C. and immunofluorescence microscopy of HeLa D. and hTERT-RPE1 cells E. (A-C): Cells were incubated for 48 hours with SAHA alone and in combination with SBE13 and analyzed for their cell cycle distribution. The graphs show the relative number of cells in the respective cell cycle phases. (D, E): Cells were incubated for $24 \mathrm{hrs}$ with SAHA alone and in combination with SBE13 and analyzed for phosphorylated $\mathrm{Rb}$ and for $\mathrm{p} 21$ protein using CLM microscopy. Red: p21, green: phospho-Rb, blue: DNA staining. Acquisition settings (exposure times) were kept constant for all images and were as follows: $200 \mathrm{~ms}$ for DAPI, $1 \mathrm{~s}$ for Alexa 488 and $500 \mathrm{~ms}$ for Cy3. Optical sections with an axial resolution of $720 \mathrm{~nm}$ (DAPI), $790 \mathrm{~nm}$ (Alexa488) and $880 \mathrm{~nm}$ (Cy3) were achieved through structured illumination employing 3 phase images without any normalization, phase correction, Fourier filtering or deconvolution. 


\section{A HeLa}

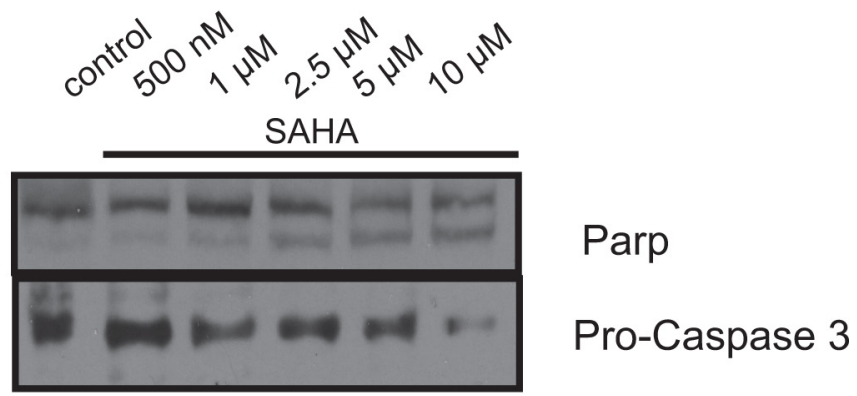

\section{B hTERT-RPE1}

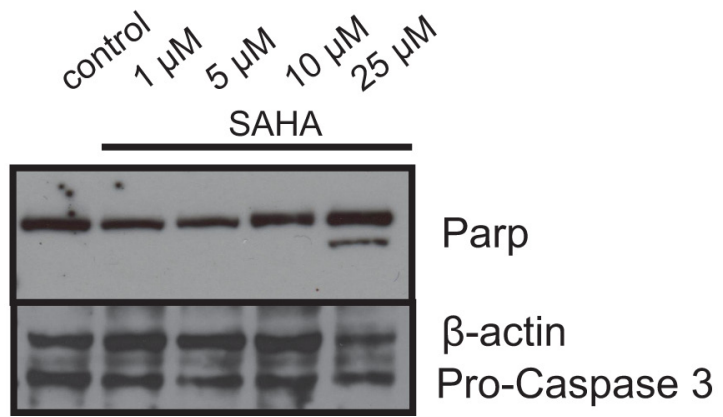

Figure 5: Western blot analyses of Parp and Caspase 3 in HeLa A. and hTERT-RPE1 cells B. after treatment with SAHA. Figures show representative blots after incubation with antibodies against Parp and Pro-Caspase 3.

after treatment with $1 \mu \mathrm{M}$ SAHA according to the Parp cleavage.

\section{Cell proliferation analysis after treatment with SAHA and SBE13 in HeLa, hTERT-RPE1 and NIH-3T3 cells}

To investigate whether the cell cycle arrest and induction of apoptosis causes a reduction of cell proliferation, we analyzed the cell proliferation of the various cell lines after treatment with SAHA alone and in combination with SBE13 (Figure 6).

HeLa cells showed a slightly reduced cell proliferation to levels of $83 \%$ with $500 \mathrm{nM}$ SAHA and to $51 \%$ with $1 \mu \mathrm{M}$ SAHA (Figure 6A). The reduction was significant with 2.5 $\mu \mathrm{M}$ SAHA $(65 \%, p=0.04)$ and with 5 and $10 \mu \mathrm{M}$ SAHA $(26 \%, p=0.02$ and $4 \%, p=0.008$, respectively) (Figure $6 \mathrm{~A})$. In combination with $1 \mu \mathrm{M}$ SBE13 we observed a significant reduction already with $500 \mathrm{nM}$ SAHA $(53 \%, p$ $=0.01)$. Together with $1 \mu \mathrm{M}$ SAHA to $39 \%, p=0.01$, with $2.5 \mu \mathrm{M}$ SAHA to $10 \%, p=0.008$, and with $5 \mu \mathrm{M}$ SAHA to $6 \%, p=0.008$. This stronger reduction in combination was synergistic with a c.i. value of 0.21 .

In contrast, hTERT-RPE1 and NIH-3T3 cells displayed a weaker combinatorial effect on the reduction of cell proliferation. hTERT-RPE1 cell proliferation was reduced to $84 \%$ with $1 \mu \mathrm{M}$ SAHA $(p=0.16$ ), to $43 \%$ with $2.5 \mu \mathrm{M}$ SAHA $(p=0.003)$, to $20 \%$ with $5 \mu \mathrm{M}$ SAHA $(p=0.004)$, to $27 \%$ with $10 \mu \mathrm{M}$ SAHA $(p=$ $0.001)$ and to $10 \%$ with $10 \mu \mathrm{M} \mathrm{SAHA}(p=0.004)$ (Figure $6 \mathrm{~B})$. The combination with SBE13 showed a slightly stronger effect on cell proliferation $(10 \mu \mathrm{M}$ SBE13 + $100 \mathrm{nM}$ SAHA reduction to $84 \%, p=0.06$, SBE13 +500 nM SAHA reduction to $74 \%, p=0.08, \mathrm{SBE} 13+1 \mu \mathrm{M}$ SAHA reduction to $45 \%, p=0.007, \mathrm{SBE} 13+2.5 \mu \mathrm{M}$ SAHA reduction to $21 \%, p=0.003$, and $\mathrm{SBE} 13+5 \mu \mathrm{M}$ SAHA reduction to $9 \%, p=0.001$ ). This combination was synergistic with a c.i. value of 0.5 , thus much less than in the HeLa cancer cells. NIH-3T3 cells showed already a very strong reduction of cell proliferation after single SAHA administration (Figure 6C) with a reduction to $70 \%$ with $1 \mu \mathrm{M}, p=0.003$, to $22 \%$ with $2.5 \mu \mathrm{M}$, $p<0.001$, to $9 \%$ with $5 \mu \mathrm{M}, p<0.001$, and to $2 \%$ with $10 \mu \mathrm{M}$ SAHA, $p<0.001$. The combination with $10 \mu \mathrm{M}$ SBE13 led to slightly stronger reduced cell proliferation: together with 100 or $500 \mathrm{nM}$ SAHA, respectively, proliferation was not reduced compared to control cells (reduction to $89 \%, p=0.138$ or 0.07 , respectively), with $1 \mu \mathrm{M}$ SAHA to $80 \%, p=0.003$, with $2.5 \mu \mathrm{M}$ to $28 \%$, $p<0.001$, and with $5 \mu \mathrm{M}$ SAHA $14 \%, p=0.001$. This reduction of cell proliferation was even not synergistic, but antagonistic (c.i. $=1.23)$ 

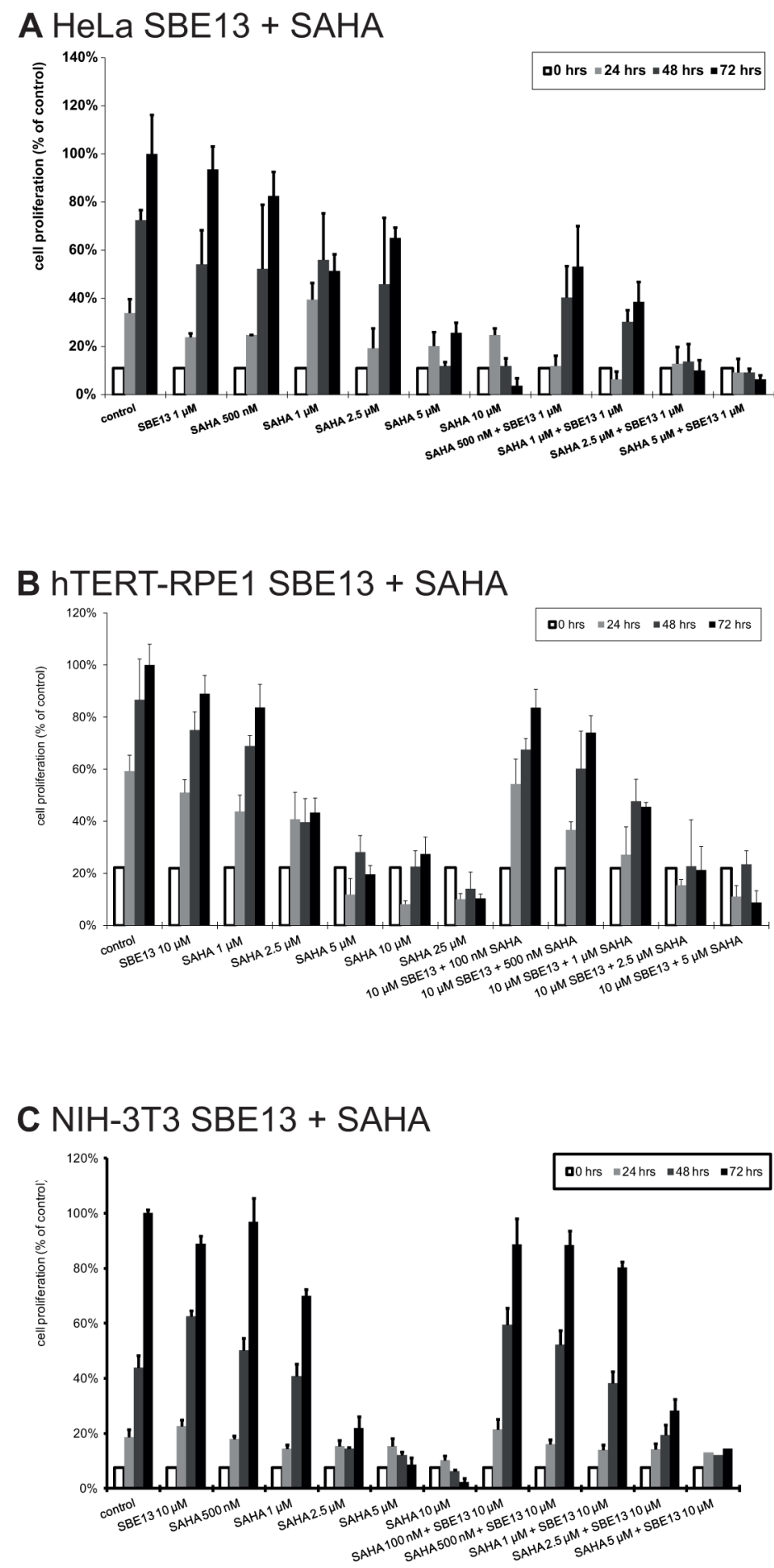

Figure 6: Cell proliferation of HeLa A. hTERT-RPE1 B. and NIH-3T3 cells C. after treatment with SAHA and SBE13. Cells were incubated for 24-72 hours with SAHA alone or in combination with SBE13 (HeLa cells: $1 \mu$ M, hTERT-RPE1 and NIH-3T3 cells: $10 \mu \mathrm{M})$. Percentage of surviving cells is given as percentage of the number of control cells after 72 hrs. Bar graphs represent means of three different experiments.

\section{DISCUSSION}

In the current study we analyzed for the first time the effects of SAHA in combination with SBE13 on cell cycle regulation, P1k1 expression, cell proliferation, and induction of apoptosis in HeLa cells, hTERTRPE1 cells and in mouse fibroblast NIH-3T3 cells. From earlier studies it is known that Plk1 depletion leads to different effects in cancer vs. non-cancer cells, and thus we analyzed this combination in cancer and 
non-cancer cells to confirm these differential effects $[18,21,24,34]$.

First we wanted to point out whether SAHA influences Plk1 transcription or protein stability. Our quantitative real-time PCR and Western blot analyses revealed a regulation of $\mathrm{Plk} 1$ at the transcriptional level by SAHA, because in cancer and non-cancer cells Plk1 mRNA levels were statistically significantly reduced by SAHA (alone and in combination with SBE13). As expected, the combination of SAHA with SBE13 did not alter Plk1 transcript levels compared to SAHA alone. To rule out an influence of increased proteasomal degradation we did Western blot analyses using MG132-treated cells, but also after addition of MG132 Plk1 levels decreased following SAHA treatment compared to controls treated with MG132 alone. This observation is in concordance with the observation of Noh et al. regarding a down-regulation of Plk1 transcripts by Trichostatin A [25]. Indeed, Plk1 is a target of the $\mathrm{Rb}$ pathway via SWI/SNF-dependent histone deacetylation of the Plk1 promoter which can explain these effects [35].

This fact motivated us to analyze $\mathrm{pRb}$ and $\mathrm{p} 21$. Our Western blot analyses revealed a differential effect between cancer and non-cancer cells concerning p21 induction and apoptosis induction. HeLa cells showed a strong induction of $\mathrm{p} 21$ protein expression and Parp cleavage as well as Caspase 3 activation, while hTERTRPE1 cells showed no p21 or apoptosis induction. In contrast to cancer cells non-transformed cells have higher basal levels of p21 as it is known that lacking of p21 leads to tumorigenesis [36]. Taking into account that we observed in earlier studies using SBE13 in HeLa cells a G2/M arrest and in hTERT-RPE1 cells a transient G0/ G1 arrest [24], we assume that the differences between HeLa and hTERT-RPE1 are due to a functional G1/S checkpoint in hTERT-RPE1 cells and to the function of p21 as well at the G1/S and the G2/M transition $[37,38]$. Another explanation for the different effects in cancer and non-cancer cells could be the localization of $\mathrm{p} 21$ : it is well-known that cytoplasmic localization of p21 leads to an inhibition of Caspase 3 activation and thus to reduced apoptosis induction, and that $\mathrm{p} 21$ has a dual role as oncogene or tumor suppressor gene dependent on its localization $[37,39,40]$. If p21 is localized in the nucleus it works as a tumor suppressor, and in the cytoplasm as an oncoprotein [40]. We detected p21 in hTERT-RPE1 cells exclusively in the nuclei, supporting its role as tumor suppressor especially in cells with functional checkpoints. Due to this localization p21 can contribute to DNA repair, induction of cell cycle arrest and work as transcriptional cofactor [40]. In contrast, in HeLa cells we found a stronger cytoplasmic localization after treatment supporting its role as an oncoprotein and confirming earlier studies from other groups showing cytoplasmic enrichment of p21 after Plk1 inhibition [40] and thus leading to a prevention of apoptosis induction in cancer cells $[39,41]$. After addition of SAHA or SAHA together with SBE13 p21 was found within the whole cell, losing its ability to prevent cells from apoptosis.

The fact that HeLa cells induce p21 after treatment with an HDAC inhibitor and hTERT-RPE1 cells do not, in combination with the observation that HeLa cells induce apoptosis while hTERT-RPE1 cells do not, is in concordance with Papeleu et al., who report that hepatoma cells show an upregulation of p21, accompanied by increasing Caspase 3 activity and subsequent apoptosis induction, while primary hepatocytes do not show this p21 induction and they do not show an activation of Caspase 3 and no signs of cell death [42]. Another publication corroborates the observation that NIH-3T3 cells show a slight induction of p21 after DNA damage, although these are non-cancer cells, because it is described that this increase can occur also in normal untransformed cells [37].

Additionally, it is known that p21 prevents Plk1 expression via direct binding of the Plk1 promoter, which may be part of an adaptive stress response [43]. Thus, generally, p21 contributes to G1 phase arrest via inhibition of Cyclin E, Cyclin A/Cdk activity and thus leaving Rb hypo-phosphorylated and sequestering E2F, whose activity is necessary for S phase entry [37]. This fits perfectly with our observation that hTERT-RPE1 cells show hypophosphorylated $\mathrm{Rb}$ protein after treatment with SBE13 and / or SAHA.

Our study is also consistent with observations identifying L-Carnitine as an endogenous HDACi, which selectively induced cytotoxic effects in cancer cells although it inhibited HDAC activity also in primary cells [44]. This confirms our observation that SAHA reduces Plk1 transcript and protein levels in both cancer and primary cells, but induces p21 and apoptosis, holds up phosphorylation of the $\mathrm{Rb}$ protein, leads to $\mathrm{G} 2 / \mathrm{M}$ enrichment and to strongly reduced cell proliferation only in cancer cells, but not in non-cancer cells.

The current study provides another hint for the importance of an intact G1/S checkpoint in primary versus cancer cells for a differential effect in cancer therapy as observed in earlier studies [24]. Here, we could show for the first time, that the $\mathrm{p} 21$ protein localizes in hTERTRPE1 cells mainly in the nucleus (in control and treated cells) confirming its role as a tumor suppressor gene [45]. In HeLa cells, in contrast, we observed many cells with cytoplasmic localization of p21, contributing to its known role as an oncoprotein, preventing apoptosis induction in HeLa cells in the absence of additional stresses. Addition of SAHA and SBE13 led to cell death of HeLa cells confirming the synergistic reduction of cell proliferation in contrast to non-cancer cells. Thus, p21 can execute its function as a tumor suppressor and G1/S regulator only in non-cancer cells, making it an interesting target for potential therapeutics. 


\section{MATERIALS AND METHODS}

\section{Kinase and HDAC inhibitors and antibodies}

The Plk1 kinase inhibitor SBE13 was purchased from the SPECS compound catalogue (Delft, Netherlands), the HDAC inhibitor SAHA was from Selleck (Absource Diagnostics GmbH München, Germany).

Monoclonal-anti-Plk1, monoclonal-anti-ProCaspase 3, goat anti-mouse and goat anti-rabbit secondary antibodies were from Santa Cruz Biotechnology, Inc., (Heidelberg, Germany), rabbit anti-phospho$\mathrm{Rb}$ antibody was from abcam (Cambridge, UK), monoclonal-anti-p21 and rabbit-anti-Parp antibodies were from Cell Signaling (Frankfurt/Main, Germany) and monoclonal $\beta$-actin-antibody was from Sigma-Aldrich (Taufkirchen, Germany). Monoclonal p21-antibody for immunofluorescence was from BD Biosciences (Heidelberg, Germany). Cy3-conjugated goat antirabbit IgG F(ab')2-fragment antibody was from Dianova (Hamburg, Germany) and Alexa488-conjugated goatanti-mouse antibody was from Jackson ImmunoResearch Laboratories (Baltimore, USA).

\section{Cell culture}

HeLa and NIH-3T3 cells were from DSMZ (Braunschweig, Germany), hTERT-RPE1 cells were from Clontech (Saint-Germain-en Laye, France). All cells were cultured according to the supplier's instructions without antibiotics. Fetal calf serum (FCS) was from PAA Laboratories (Cölbe, Germany), MEM, DMEM, DMEM F12, phosphate buffered saline (PBS), glutamine, and trypsin were from Invitrogen (Karlsruhe, Germany).

\section{Treatment and analysis of cells}

Cells were treated with SBE13 and SAHA alone or in combination one day after subculturing. Cells were seeded onto 6-well-plates, or 75- $\mathrm{cm}^{2}$ - flasks, respectively. Control cells were incubated with normal culture medium without antibiotics. Concentrations of SBE13 were $1 \mu \mathrm{M}$ for cancer cells and $10 \mu \mathrm{M}$ for non-cancer cells, respectively, SAHA concentrations ranged from $0.1-10 \mu \mathrm{M}$. The growth rate of $5 \times 10^{4}$ cells per 6 -well was determined by counting cells at 24 to 72 hours after treatment using a hematocytometer. Cell culture studies were performed in triplicate for each time point. Cells were harvested 24-72 hours after treatment for further analyses.

\section{Quantitative real-time PCR analysis}

After isolation of total RNA using RNeasy mini-kits (Qiagen, Hilden, Germany) according to the manufacturer's protocol $24 \mathrm{hrs}$ after incubation with SAHA alone or together with SBE13, respectively, the mRNA was transcribed into cDNA using the High-Capacity
cDNA Reverse Transcription Kits (Applied Biosystems, Darmstadt, Germany). Thereafter, 50 ng cDNA were subjected to quantitative real-time PCR analyses targeting Plk1 and GAPDH using the FastStart Universal Probe Master ROX and Universal ProbeLibrary \#30 (Plk1) and \#60 (GAPDH) (Roche Applied Biosciences, Mannheim, Germany). Primer sequences were chosen as suggested by Roche Applied Biosciences (Mannheim, Germany): Plk1 forward 5'-cacagtgtcaatgcctccaa, Plk1 reverse 5'-ttgctgacccagaagatgg, GAPDH forward 5'-agccacatcgctcagacac, GAPDH reverse 5 '-geccaatacgaccaaatcc. Analysis was performed using the StepOne Plus RealTime PCR System and the StepOne v2.2.3 software (Applied Biosystems, Darmstadt, Germany). Relative gene expression values were determined by the $\Delta \Delta \mathrm{C}_{\mathrm{T}}$ method using the StepOne v2.3 software (Applied Biosystems, Darmstadt, Germany). Data are presented as the fold difference in Plk1 expression normalized to the housekeeping gene GAPDH as endogenous reference, and relative to the untreated control cells.

\section{Western blot analysis}

Total protein $(50 \mu \mathrm{g})$ was separated on $10 \%$ BisTris-polyacrylamide gels and transferred (at $30 \mathrm{~V}$ for $1 \mathrm{hr}$ ) to Immobilon ${ }^{\mathrm{TM}}$-P membranes (Millipore, Bedford, MA) according to the Invitrogen protocol (Karlsruhe, Germany). Membranes were incubated for $1 \mathrm{hr}$ in $5 \%$ powdered nonfat milk in PBS with antibodies against Plk1 (1:200), Pro-Caspase 3 (1:1,000), p21 (1:2,000), $\mathrm{pRb}(1: 2,000)$, Parp $(1: 1,000)$ or $\beta$-actin $(1: 100,000)$ and for $30 \mathrm{~min}$ in $5 \%$ nonfat dry milk with goat anti-mouse or goat anti-rabbit serum $(1: 2,000)$ and visualized as described [21].

All protein expression levels were presented as described [21], scanned and quantified with the freeware ImageJ (National Institutes of Health, USA).

\section{FACS analysis}

Cell cycle distribution was analyzed using a FACScalibur apparatus (Becton Dickinson, Heidelberg, Germany). Quantification was carried out using ModFit LT 3.3 for Windows (Verity Software House, Topsham, ME). For FACS analysis, cells were harvested at the indicated time points, washed with PBS, fixed and stained as described [46]. For each experiment, 30, 000 cells were analyzed in triplicate.

\section{Immunofluorescence analysis}

Immunofluorescence optical sectioning microscopy was performed on an AxioObserver microscope equipped with a ApoTome. 2 structured illumination unit using a 63x/1.4 NA oil immersion Plan-Apochromat objective (Carl Zeiss, Jena, Germany). DAPI, Alexa488 and Cy3 
dyes were excited through dye-specific optical filters at $335-383 \mathrm{~nm}, 450-490 \mathrm{~nm}$ and 538-562 nm, respectively at $50 \%$ constant output of a HXP120 fluorescence excitation light source. DAPI, Alexa488 and Cy3 fluorescence was captured with dye-specific band pass filters at 420 $470 \mathrm{~nm}, 500-550 \mathrm{~nm}$ and 570-640 nm, respectively. Beamsplitters at $395 \mathrm{~nm}, 495 \mathrm{~nm}$, and $570 \mathrm{~nm}$ were used, respectively. There was no bleedthrough or cross-talk in the triple-fluorescence staining experiments using these filter combinations. Each dye was scanned independently in multitracking mode. Optical sections were acquired for each color channel at mid-nucleus postion after selection in the z-axis using an Axiocam 503 mono camera (Zeiss) at $1936 \times 1460$ pixels (72 nm per pixel). Acquisition settings (exposure times) were kept constant for all images and were as follows: $200 \mathrm{~ms}$ for DAPI, $1 \mathrm{~s}$ for Alexa 488 and $500 \mathrm{~ms}$ for Cy3. Optical sections with an axial resolution of $720 \mathrm{~nm}$ (DAPI), $790 \mathrm{~nm}$ (Alexa488) and $880 \mathrm{~nm}$ (Cy3) were achieved through structured illumination employing 3 phase images without any normalization, phase correction, Fourier filtering or deconvolution.

ZEN 2 pro software (Carl Zeiss) was used for image acquisition, display and export as TIF files. Micrographs were assembled from TIF files using Photoshop software.

We analyzed phospho-Rb to analyze the G1/S checkpoint control and p21 localization. DNA was stained with 2-(4-amidinophenyl)-6-indolecarbamidine dihydrochloride (DAPI) (Sigma-Aldrich, Taufkirchen, Germany). Polyclonal anti-pRb antibodies were used at a 1:250 dilution in 1\% BSA (Sigma-Aldrich, Taufkirchen, Germany) in PBS, p21 antibodies at a 1:100 dilution in 1\% in PBS.

\section{Statistical methods}

All experiments were performed at least in triplicate. All treatments were compared with untreated control cells. Statistical analysis was performed with student's $t$-test and ANOVA to consider random effects as described [21]. $E C_{50}$ values were calculated from the cell proliferation experiments assuming the cell number of control cells at the latest time point as $100 \%$.

The combination index was calculated using the following equation: c.i. $=(\mathrm{Am})_{50} /(\mathrm{As})_{50}+(\mathrm{Bm})_{50} /(\mathrm{Bs})_{50}$, where $(\mathrm{Am})_{50}$ is the concentration of drug A necessary to achieve a $50 \%$ inhibitory effect $\left(I C_{50}\right)$ in the combination, $(\mathrm{As})_{50}$ is the concentration of the same drug that will produce the identical level of effect alone, $(\mathrm{Bm})_{50}$ is the $I C_{50}$ of drug $\mathrm{B}$ in the combination and $(\mathrm{Bs})_{50}$ is the $I C_{50}$ of drug $\mathrm{B}$ after single administration. Antagonism is indicated when c.i. $>1$, c.i. $=1$ indicates an additive effect and a c.i. $<1$ indicates synergy [47].

\section{ACKNOWLEDGMENTS}

We are very grateful to the Wilhelm-Sander-Stiftung (2009.024.1), the Deutsche Krebshilfe, the Messer-Stiftung and to JenAge http://www.jenage.de/foswiki/bin/view/ JenAge/JenAge for funding by the German Ministry for Education and Research (Bundesministerium für Bildung und Forschung BMBF; support code: 0315581).

We are also very grateful to Dr. N.-N. Kreis, Dr. S. Keppner-Witter and Dr. T. Heinzel for helpful discussions and to Dr. T. Heinzel for providing working facilities. We also thank M. Koch, P. Schmerer, P. Bohm, D. Yüzen, K. Kullmann, A.K. Kistenmacher, L. Drechsel and A.B. Hums for assistance with the experiments.

\section{REFERENCES}

1. Glover DM, Hagan IM, Tavares AA. Polo-like kinases: a team that plays throughout mitosis. Genes Dev. 1998; 12:3777-3787.

2. Holtrich U, Wolf G, Brauninger A, Karn T, Bohme B, Rubsamen-Waigmann H, Strebhardt K. Induction and down-regulation of PLK, a human serine/threonine kinase expressed in proliferating cells and tumors. Proc Natl Acad Sci U S A. 1994; 91:1736-1740.

3. Strebhardt K, Ullrich A. Targeting polo-like kinase 1 for cancer therapy. Nat Rev Cancer. 2006; 6:321-330.

4. Schmit TL, Zhong W, Nihal M, Ahmad N. Polo-like kinase 1 (Plk1) in non-melanoma skin cancers. Cell Cycle. 2009; 8:2697-2702.

5. Toyoshima-Morimoto F, Taniguchi E, Shinya N, Iwamatsu A, Nishida E. Polo-like kinase 1 phosphorylates cyclin B1 and targets it to the nucleus during prophase. Nature. 2001; 410:215-220.

6. Toyoshima-Morimoto F, Taniguchi E, Nishida E. Plk1 promotes nuclear translocation of human Cde25C during prophase. EMBO Rep. 2002; 3:341-348.

7. Yuan J, Eckerdt F, Bereiter-Hahn J, Kurunci-Csacsko E, Kaufmann M, Strebhardt K. Cooperative phosphorylation including the activity of polo-like kinase 1 regulates the subcellular localization of cyclin B1. Oncogene. 2002; 21:8282-8292.

8. Cogswell JP, Brown CE, Bisi JE, Neill SD. Dominantnegative polo-like kinase 1 induces mitotic catastrophe independent of cdc25C function. Cell Growth Differ. 2000; 11:615-623.

9. van de Weerdt BC, Medema RH. Polo-like kinases: a team in control of the division. Cell Cycle. 2006; 5:853-864.

10. Eckerdt F, Yuan J, Strebhardt K. Polo-like kinases and oncogenesis. Oncogene. 2005; 24:267-276.

11. Rodel F, Keppner S, Capalbo G, Bashary R, Kaufmann M, Rodel C, Strebhardt K, Spankuch B. Polo-like kinase 1 as predictive marker and therapeutic target for radiotherapy in rectal cancer. Am J Pathol. 2010; 177:918-929.

12. Liu X, Erikson RL. Polo-like kinase (Plk)1 depletion induces apoptosis in cancer cells. Proc Natl Acad Sci U S A. 2003; 100:5789-5794. 
13. Nogawa M, Yuasa T, Kimura S, Tanaka M, Kuroda J, Sato K, Yokota A, Segawa H, Toda Y, Kageyama S, Yoshiki T, Okada Y, Maekawa T. Intravesical administration of small interfering RNA targeting PLK-1 successfully prevents the growth of bladder cancer. J Clin Invest. 2005; 115:978-985.

14. Ahmad N. Polo-like kinase (Plk) 1: a novel target for the treatment of prostate cancer. FASEB J. 2004; 18:5-7.

15. Lane HA, Nigg EA. Antibody microinjection reveals an essential role for human polo-like kinase 1 (Plk1) in the functional maturation of mitotic centrosomes. J Cell Biol. 1996; 135:1701-1713.

16. Keppner S, Proschak E, Kaufmann M, Strebhardt K, Schneider G, Spankuch B. Biological impact of freezing Plk1 in its inactive conformation in cancer cells. Cell Cycle. 2010; 9:761-774.

17. Keppner S, Proschak E, Schneider G, Spankuch B. Identification and validation of a potent type II inhibitor of inactive polo-like kinase 1. ChemMedChem. 2009; 4:1806-1809.

18. Spankuch B, Kurunci-Csacsko E, Kaufmann M, Strebhardt K. Rational combinations of siRNAs targeting Plk1 with breast cancer drugs. Oncogene. 2007; 26:5793-5807.

19. Spankuch B, Matthess Y, Knecht R, Zimmer B, Kaufmann M, Strebhardt K. Cancer inhibition in nude mice after systemic application of U6 promoter-driven short hairpin RNAs against PLK1. J Natl Cancer Inst. 2004; 96:862-872.

20. Spankuch-Schmitt B, Wolf G, Solbach C, Loibl S, Knecht R, Stegmuller M, von Minckwitz G, Kaufmann M, Strebhardt K. Downregulation of human polo-like kinase activity by antisense oligonucleotides induces growth inhibition in cancer cells. Oncogene. 2002; 21:3162-3171.

21. Spankuch-Schmitt B, Bereiter-Hahn J, Kaufmann M, Strebhardt K. Effect of RNA Silencing of Polo-Like Kinase-1 (PLK1) on Apoptosis and Spindle Formation in Human Cancer Cells. J Natl Cancer Inst. 2002; 94:1863-1877.

22. Yoo HY, Kumagai A, Shevchenko A, Shevchenko A, Dunphy WG. Ataxia-telangiectasia mutated (ATM)dependent activation of ATR occurs through phosphorylation of TopBP1 by ATM. J Biol Chem. 2007; 282:17501-17506.

23. Li H, Wang Y, Liu X. Plk1-dependent phosphorylation regulates functions of DNA topoisomerase IIalpha in cell cycle progression. J Biol Chem. 2008; 283:6209-6221.

24. Keppner S, Proschak E, Schneider G, Spankuch B. Fate of primary cells at the $\mathrm{G} 1 / \mathrm{S}$ boundary after polo-like kinase 1 inhibition by SBE13. Cell Cycle. 2011; 10:708-720.

25. Noh EJ, Lim DS, Jeong G, Lee JS. An HDAC inhibitor, trichostatin $\mathrm{A}$, induces a delay at G2/M transition, slippage of spindle checkpoint, and cell death in a transcription-dependent manner. Biochem Biophys Res Commun. 2009; 378:326-331.
26. Lee JS. Activation of ATM-dependent DNA damage signal pathway by a histone deacetylase inhibitor, trichostatin A. Cancer Res Treat. 2007; 39:125-130.

27. Kramer OH, Gottlicher M, Heinzel T. Histone deacetylase as a therapeutic target. Trends Endocrinol Metab. 2001; 12:294-300

28. Bug G, Ritter M, Wassmann B, Schoch C, Heinzel T, Schwarz K, Romanski A, Kramer OH, Kampfmann M, Hoelzer D, Neubauer A, Ruthardt M, Ottmann OG. Clinical trial of valproic acid and all-trans retinoic acid in patients with poor-risk acute myeloid leukemia. Cancer. 2005; 104:2717-2725.

29. Finzer P, Kuntzen C, Soto U, zur HH, Rosl F. Inhibitors of histone deacetylase arrest cell cycle and induce apoptosis in cervical carcinoma cells circumventing human papillomavirus oncogene expression. Oncogene. 2001; 20:4768-4776.

30. Shin HJ, Baek KH, Jeon AH, Kim SJ, Jang KL, Sung YC, Kim CM, Lee CW. Inhibition of histone deacetylase activity increases chromosomal instability by the aberrant regulation of mitotic checkpoint activation. Oncogene. 2003; 22:3853-3858.

31. Rosato RR, Almenara JA, Grant S. The histone deacetylase inhibitor MS-275 promotes differentiation or apoptosis in human leukemia cells through a process regulated by generation of reactive oxygen species and induction of p21CIP1/ WAF1 1. Cancer Res. 2003; 63:3637-3645.

32. Nguyen DM, Schrump WD, Chen GA, Tsai W, Nguyen P, Trepel JB, Schrump DS. Abrogation of p21 expression by flavopiridol enhances depsipeptide-mediated apoptosis in malignant pleural mesothelioma cells. Clin Cancer Res. 2004; 10:1813-1825.

33. Ocker M, Schneider-Stock R. Histone deacetylase inhibitors: signalling towards p21cip1/waf1. Int J Biochem Cell Biol. 2007; 39:1367-1374.

34. Liu X, Lei M, Erikson RL. Normal cells, but not cancer cells, survive severe Plk1 depletion. Mol Cell Biol. 2006; 26:2093-2108.

35. Gunawardena RW, Siddiqui H, Solomon DA, Mayhew CN, Held J, Angus SP, Knudsen ES. Hierarchical requirement of SWI/SNF in retinoblastoma tumor suppressor-mediated repression of Plk1. J Biol Chem. 2004; 279:29278-29285.

36. Martin-Caballero J, Flores JM, Garcia-Palencia P, Serrano M. Tumor susceptibility of p21(Waf1/Cip1)deficient mice. Cancer Res. 2001; 61:6234-6238.

37. Cazzalini O, Scovassi AI, Savio M, Stivala LA, Prosperi E. Multiple roles of the cell cycle inhibitor p21(CDKN1A) in the DNA damage response. Mutat Res. 2010; 704:12-20.

38. Kreis NN, Sanhaji M, Rieger MA, Louwen F, Yuan J. p21Waf1/Cip1 deficiency causes multiple mitotic defects in tumor cells. Oncogene. 2014; 33:5716-5728.

39. Blagosklonny MV. Are p27 and p21 cytoplasmic oncoproteins? Cell Cycle. 2002; 1:391-393. 
40. Kreis NN, Louwen F, Zimmer B, Yuan J. Loss of p21Cip1/ CDKN1A renders cancer cells susceptible to Polo-like kinase 1 inhibition. Oncotarget. 2015; 6:6611-6626.

41. Gartel AL, Tyner AL. The role of the cyclin-dependent kinase inhibitor p21 in apoptosis. Mol Cancer Ther. 2002; 1:639-649.

42. Papeleu P, Vanhaecke T, Elaut G, Vinken M, Henkens T, Snykers S, Rogiers V. Differential effects of histone deacetylase inhibitors in tumor and normal cells-what is the toxicological relevance? Crit Rev Toxicol. 2005; 35:363-378.

43. Cholewa BD, Liu X, Ahmad N. The role of polo-like kinase 1 in carcinogenesis: cause or consequence?. Cancer Res. 2013; 73:6848-6855.

44. Huang H, Liu N, Guo H, Liao S, Li X, Yang C, Liu S, Song W, Liu C, Guan L, Li B, Xu L, Zhang C, et al.
L-carnitine is an endogenous HDAC inhibitor selectively inhibiting cancer cell growth in vivo and in vitro. PLoS One. 2012; 7:e49062.

45. Kreis NN, Louwen F, Yuan J. Less understood issues: p21 in mitosis and its therapeutic potential. Oncogene. 2014; 0 .

46. Spankuch B, Heim S, Kurunci-Csacsko E, Lindenau C, Yuan J, Kaufmann M, Strebhardt K. Down-regulation of Polo-like Kinase 1 Elevates Drug Sensitivity of Breast Cancer Cells In vitro and In vivo. Cancer Res. 2006; 66:5836-5846.

47. Chou TC, Talalay P. Quantitative analysis of dose-effect relationships: the combined effects of multiple drugs or enzyme inhibitors. Adv Enzyme Regul. 1984; 22:27-55. 